DOI : $\underline{\text { https://doi.org/10.3126/njmr.v2i3.26970 }}$

\title{
A Qualitative Study of Food Choices of School Adolescents in Nepal
}

\author{
Dr. Maya Nath Ghimire ${ }^{1} \&$ Sarita Devi Adhikari ${ }^{2}$ \\ 1 Operation Incharge and Development Expert, Nepal Philosophical Research Center \\ (NPRC), Kathmandu, Nepal \\ mayanathghimire@gmail.com \\ 2 Secondary Level Teacher, Gyanodaya Secondary School, Sahilitar, Lamjung \\ neupane.sarita@gmail.com
}

\begin{abstract}
The study was conducted in three districts: Lamjung, Chitawan and Kathmandu. All the participants were 14-19 years adolescents. The study was conducted face to face interview method. The findings show that almost adolescents' normal ffod items for lunch and dinner are Pulse, Rice, Vegetable curry, pickle and meat (weekly or on a special day). All the young like dumplings, chowmin, tea and biscuits or cookies, egg, grams, and Haluwa (Porridge). Some adolescents from Lamjung take pop-corn and fried beans as day meal. Adolescents from Kathmandu and Chitawan mostly like junk food mainly Chatpat.
\end{abstract}

Keywords: Adolescents, Food choices, Qualitative Study

\section{Introduction}

Adolescent refers to 10-19 years age. This period is transitional period between dependent childhood and independent adulthood. Adolescent comprises of about $20 \%$ of total population, more than that $80 \%$ of adolescents live in developing and under developed countries (Roba, Abdo, \& Wakayo, 2016, p. 1). During this period, adolescents go under many changes: physical, psychological, environmental and social. Adolescents are nutritionally vulnerable due to their high requirements for growth, eating patterns and their susceptibility to environmental influences. Inadequate nutrition in adolescence can potentially retard growth and sexual maturation. Inadequate nutrition also puts adolescent at high risk of chronic disease although the detrimental effects appear after a long time (Government of Nepal, Nepal Health Research Council, 2016, p. 1).

Food consumption during adolescence is important for growth and development. During this period, the energy and nutrient requirements needed are higher compared with any other part of the lifecycle (Suhaila Abdul, Ruzita Abdul, \& Norimah A, 2019, p. 22). According to Natalie McGill (Natalie, 2016) the road to good health in adulthood is cemented with the results made during the teenage years. And as teen girls and boys continue to grow, there are daily nutrients and behaviors they'll need to keep them happy and fit. It is commonly stated that food choice is a very complicated process along with we make several food choices every day based on more or less conscious decisions (Neupane, 2019, p. 182). Furthermore, “... industrialization and urbanization has changed consumption pattern. The rural setting has its own pattern of food consumption based on availability of food according to season, and availability of food items 
found in the consumers' own farmland. However, urban people have more choices in food items" (Neupane, 2018, p. 73).

In 2005, Dapi and colleagues (Dapi, Nouedoui, Janlert, \& Haglin, 2005) conducted a study on "Adolescents' food habits and nutritional status in urban and rural areas in Cameroon, Africa". This study aimed to describe and compare food habits and nutritional status of adolescents in Cameroon. The design of the study was a cross-sectional study using an un-quantified food frequency questionnaire and anthropometric data, in urban and rural areas. There were 52 adolescents, 12-15 years old, were selected from schools. The results showed that frequencies of consumption of meat, vegetables, cereals, milk products and junk food were significantly higher in urban than in rural adolescents. The frequency of in-between meals was higher in urban than in rural adolescents. Arm muscle area (AMA, $\mathrm{mm}^{2}$ ) and waist/hip ratio were significantly higher in rural than in urban adolescents. Body mass index (BMI, kg $\mathrm{m}^{2}$ ) was higher in rural than urban adolescents, although not significant. There was a positive significant correlation between BMI and AMA in urban and rural areas.

Similarly, in 2012 Hoffmann and colleagues (Hoffmann, Bryl, Marcinkowski, Rzesoś, Wojtyła, $\&$ Pupek-Musialik, 2012) conducted a study on "Dietary behaviours of adolescents from urban and rural areas in the district of Szamotuly - a preliminary study". The aim of the study was to describe dietary behaviours of two young populations: living in urban or rural areas in the district of Szamotuly. The research deign of the study was quantitative a cross-sectional. There were 116 adolescents aged 15-17 years and they were asked to answer questions concerning health and lifestyle. The results showed that no statistically significant difference was detected in the number of meals eaten daily, and 3 meals a day was the most frequent answer $(45.9 \%$ in the rural group and $32.7 \%$ in the urban group). About $41.0 \%$ of rural subjects and $50.9 \%$ of urban ones admitted that they ate fresh fruit and vegetables every day. There was no statistically significant difference in the medium consumption frequency of fresh fruit, vegetable, fish, sweets and salty snacks. The study recommends that there is a great need to change the dietary habits of teenagers, especially in avoiding an over-intake of high fat and high energy products, in order to reduce the rising prevalence of obesity among adolescents.

All the above mentioned researches from different nations have showed the changing pattern of food habits of teenagers. Now the time has come to us from Nepal too, to pay attention in food choice patterns of Nepalese teenagers.

\section{Objective}

- To explore status of Nepalese adolescents' food choice.

\section{Methodology:}

The research was an explorative based on qualitative method. The study was conducted in Lamjung, Chitawan and Kathmandu districts, Nepal. Eligible participants were 14-19 year old school adolescents (boys and girls). The data were collected from in depth-interviews with semistructure questionnaire.

While talking about the philosophical foundation, philosophical stance guides the researcher about the way in which he data about a phenomenon is gathered, analyzed and used. So research paradigm in a qualitative research acts as the guide of any research since it talks about the 
existence of knowledge, nature of knowledge and how that knowledge can be acquired. It also deals with the researchers and their existence as well. Research paradigm is a collection of belief, which guides any researcher to decide what can be studied and how results can be interpreted. We decided to use the interpretive and critical paradigm for our research work. According to Cohen and Mahion (2007, p. 638), interpretive are concerned with understanding the subjective world of the human experience by interviewing or observing the participants. This paradigm gives importance to subjective relationship between the researcher and subject. It also helps the researchers to conduct this study in natural environment where the female participation is practiced.

Total 30 respondents were participated in in-depth interview through random sampling method, 10/10 respondents from Lamjung, Chitawan and Kathmandu. For data collection, face to face interview was used. Data were compiled, analyzed, and prepared research report.

\section{Results}

School adolescents from Lamjung, Chitawan and Kathmandu districts of Nepal participated in individual level in-depth interview in the following areas. Respondents' answers were concised and prepared reports accordingly.

\subsection{General information}

The age of respondents varied from 14 to 19 years. Among them 18 girls and 12 were boys. The respondents were also asked their father's occupation. They reported as teacher, army, police, manager, international labor, business, pharmacy doctor, photographer, and mason. Father education was found literate to BA (graduated). Mother's occupation was reported as house maker, librarian, accountant and supported in business. The education of mother was found literate to BA (graduated).

\subsection{Normal food items consumed during breakfast, lunch, snacks and dinner:}

The respondents were asked about the normal food items served for breakfast, lunch, snacks and dinner. During breakfast, tea, biscuits, milk, cheese, bread, gram and egg are consumed. For lunch and dinner, they consume lintel, rice, vegetable curry and pickle in general. Some of the respondents from Lamjung district reported that occasionally they consume Dhindo (millet and maize porridge). For snacks, they consume Momo, readymade noodles, steamed noodles, gram, egg, chapatti, sandwich, porridge, popcorn and fried soyabean.

\section{Special food items consumed in holiday and special day:}

The respondents were also asked them about special food items that are served during special days. They reported that they are served pulau (pilaf), meat varieties (mutton, chicken, fish, pork, buff), varieties of vegetable curry, rice, lintel, pickle, curd, fruits, papad, prawn, mo:mo, cold drinks, chatpat, cookies, cetc.

\subsection{Preferred food items:}

The respondents were also asked their preferred food items. They prefer pulau (pilaf), meat varieties (mutton, chicken, fish, pork, buff), varieties of vegetable curry, rice, lintel, pickle, curd, fruits, papad, prawn, mo:mo, cold drinks, jam, bread, etc. 


\subsection{Preferred for:}

There might be different reasons why someone prefers special food item. To explore the reasons behind it, the respondents were also asked the reasons. Their opinions are recorded as: just food habit, sweet/own taste, like, daily easily available, easily prepared in home, affordable, nutritious for health growth and development.

\subsection{Does mother prepare food items according to your choices?:}

All the respondents replied sometimes yes, but not always.

\subsubsection{Why Mom cooks according to your choices:}

For this inquiry, the respondents replied that their parents love them. By laughing, some respondents replied that their parents prepared preference food items especially in holidays for wishing high scores in exam.

\subsubsection{Why Mom does not cook according to your preference:}

They were also asked why not their mothers prepare food items what they prefer. They replied that they need extra time and money.

\subsubsection{Do you want to add your opinions about food consumption?:}

For the above query, 7-8 respondents added following tips:

- As far as possible we have to consume organic products.

- Do not eat Junk foods and market made food items; they are not good for health.

- Every day do not eat same food items, use different food items alternatively.

- Use fresh and healthy food items that help in development and growth of adolescent health.

- $\quad$ Eat less fat, chilly and salt used food items.

\section{Conclusion:}

The main aim of this study was to explore food choices of adolescents of Nepal. Most of the teenagers like normal food items: pulse, rice, chapati and vegetables. Some of them from Lamjung like Maize and Millet Dhindo (Porridge) in their lunch and dinner. The breakfast items are tea, milk, jam \& bread, egg and pop-corn. In snacks, they prefer Momo, Chowmin, readymade noodles and Chatpat (Junk foods). A few respondents from Lamjung reported that they take pop-corn and fried soybean as snacks.

\section{References}

Cohen, L., \& Mahion, L. (2007). Research method in education. British Journal of Education Studies, 55(4).

Dapi, L., Nouedoui, N. C., Janlert, U., \& Haglin, L. (2005). Adolescents' food habits and nutritional status in urban and rural areas in Cameroon, Africa. Scandinavian Journal of Nutrition, 49(4), 151-158.

Government of Nepal, Nepal Health Research Council. (2016). Adolescent Nutrition Survey in Nepal 2014. Kathmandu: Government of Nepal , Nepal Health Research Council.

Hoffmann, K., Bryl, W., Marcinkowski, J. T., Rzesoś, A., Wojtyła, E., \& Pupek-Musialik, D. (2012). Dietary behaviours of adolescents from urban and rural areas in the district of Szamotuły - a preliminary study. Annals of Agricultural and Environmental Medicine, 19(1), 103-107.

Natalie, M. (2016). Teen nutrition: Making healthy food choices easy. The NATION'S HEALTH A PUBLICATION OF THE AMERICAN PUBLIC HEALTH ASSOCIATION. 
Neupane, D. (2018). Food Choice Motives of Guardians of Trilok Academy Kathmandu with reference to Gender. Nepal Journal of Multidisciplinary Research, 1(1), 73-81.

Neupane, D. (2019). Food choice motives of adults from Kathmandu city with reference to ethnicity. International Journal of Applied Research, 5(3), 182-185.

Roba, K., Abdo, M., \& Wakayo, T. (2016). Nutritional Status and Its Associated Factors among School Adolescent Girls in Adama City, Central Ethiopia. Journal of Nutrition \& Food Sciences, 6(3), 1-8.

Suhaila Abdul, G., Ruzita Abdul, T., \& Norimah A, K. (2019, April). Food Choices and Diet Quality in the School Food Environment: A Qualitative Insight from the Perspective of Adolescents. Malaysian Journal of Medicine and Health Sciences, 15, 16-24. 